\title{
Optimal waist cutpoint for screening for dysglycaemia and metabolic risk: evidence from a Maori cohort
}

\author{
Elaine C. Rush ${ }^{1}$, Nic Crook $^{2}$ and David Simmons ${ }^{3}$ \\ ${ }^{1}$ Faculty of Health and Environmental Sciences, Auckland University of Technology, Private Bag 92006, Auckland 1142, \\ New Zealand \\ ${ }^{2}$ Lakes District Health Board, Rotorua, New Zealand \\ ${ }^{3}$ Cambridge University Hospitals NHS Foundation Trust, Cambridge, UK \\ (Received 12 November 2008 - Revised 8 January 2009 - Accepted 23 January 2009 - First published online 31 March 2009)
}

We sought to identify the sex-specific cut-off in waist circumference which best identifies those with metabolic abnormalities consistent with the metabolic syndrome (MS) among Maori, the indigenous people of New Zealand of Polynesian origin. In 3816 self-identified Maori (2742 women, 1344 men) a $75 \mathrm{~g}$ oral glucose tolerance test, fasting lipid, anthropometric and blood pressure measurements were made. MS components were defined by Adult Treatment Panel (ATP) III criteria. Waist cut-off was defined using receiver operating characteristic (ROC) curve analysis to define the presence of at least two of the other MS components ( $\geq 2 \mathrm{MS})$. Prevalence of $\geq 2 \mathrm{MS}$ was high $(42 \cdot 1 \%)$. In males and females, waist was as good, or better, a predictor of $\geq 2 \mathrm{MS}$ (area under ROC 0.73 women, 0.68 men) as waist:hip ratio (0.66, 0.67), BMI (0.72, 0.68) or percentage body fat $(0.70,0.68)$. The prediction of dysglycaemia using anthropometric variables followed a similar pattern to $\geq 2 \mathrm{MS}$. Waist circumference to predict $\geq 2 \mathrm{MS}$ or dysglycaemia in Maori women and men was $98 \mathrm{~cm}$ and $103 \mathrm{~cm}$. Applying this cut-off to the International Diabetes Federation (IDF) criteria would identify $27.8 \%$ (34.0\% males, $25.5 \%$ females) with the MS with an OR for $\geq 2$ MS (adjusted for sex, smoking and age) of 3.5 (95\% CI 3.1, 4.0). Age $>48$ years, smoking and being male increased the odds of the MS. These waist cut-offs should be considered in both clinical practice and to optimise the definition of the MS for Maori. The validity of these criteria in other Polynesian groups should be confirmed.

Waist: Metabolic syndrome: Dysglycaemia: Dyslipidaemia: Maori

There remains debate over the existence ${ }^{(1,2)}$ and definition $^{(3,4)}$ of the metabolic syndrome (MS). Both the Adult Treatment Panel (ATP) III ${ }^{(5)}$ criteria and the International Diabetes Federation (IDF) ${ }^{(4,6)}$ accept that waist, as a measure of central obesity, is more highly associated with metabolic risk factors than waist:hip ratio (WHR), BMI or body fat percentage. ATPIII and IDF criteria for fasting glucose, TAG, HDL-cholesterol and blood pressure are identical ${ }^{(7)}$, but the waist cut-off differs (for example, among Europeans, ATPIII $v$. IDF criteria $102 \mathrm{~cm} v .94 \mathrm{~cm}$ (men) and $88 \mathrm{~cm} v$. $80 \mathrm{~cm}$ (women) respectively). The combinations of classification criteria also differ: for ATPIII it is any three criteria that may or may not include waist and for IDF waist is mandatory with any two other criteria. Waist measurement is a simple and clinically useful measure as an initial screen for further testing for metabolic risk factors. While it would be useful to classify subjects according to metabolic or disease outcomes this requires longitudinal studies with the additional problem that the waist measurement changes with the disease process.
It is recognised that there are ethnic differences in MS classification criteria and utility in the Asia Pacific region ${ }^{(8)}$ and the IDF recommends different ethnic group- and country-specific waist cut-offs ${ }^{(4,9)}$. Neither approach includes cut-offs that apply to people of Polynesian origin such as the indigenous New Zealand Polynesian population, Maori. It is established that for the same height and weight Polynesian people have less fat and are more lean than Europeans ${ }^{(10,11)}$ : obesity in adult Polynesians is defined as a BMI $>32 \mathrm{~kg} / \mathrm{m}^{2}$. No waist criteria have been defined for Polynesians, a group with a high prevalence ${ }^{(12)}$ of known type 2 diabetes $(8 \%)$ and CVD $(12 \%)^{(13)}$ as well as obesity $(>25 \%)$ and smoking $(>45 \%)$. The early identification of individuals most at risk in this high-risk population may allow more timely intervention (for example, through targeted intensive lifestyle interventions $\left.{ }^{(14-16)}\right)$.

In the present study, we investigated optimal waist cut-offs, in a Maori cohort without known diabetes, to identify subjects with two or more risk factors for diabetes and/or CVD. This analysis aims to answer a practical question - which

Abbreviations: ATP, Adult Treatment Panel; IDF, International Diabetes Federation; MS, metabolic syndrome; $\geq 2$ MS, at least two of the other metabolic syndrome components; ROC, receiver operating characteristic; WHR, waist:hip ratio.

* Corresponding author: Professor Elaine Rush, fax +649921 9960, email Elaine.rush@aut.ac.nz 
waist cut-off best identifies subjects with risk factors (blood pressure, glucose and lipids) that characterise the MS? A secondary aim was to identify whether WHR, BMI or percentage body fat would also be useful to identify subjects at risk.

\section{Research design and methods}

The population included was defined by the boundaries of the Waikato District Health Board, and the tribal area of Ngati TuWharetoa in the neighbouring Lakes District Health Board as previously described ${ }^{(17)}$. The age cut-off for entry was set at 28 years and over on 30 September 2005. Maori with past gestational diabetes mellitus, and those aged 23 years and over with two parents with known diabetes, were also considered eligible. Those with known diabetes, who were unfit to sign a consent form, with terminal disease or not permanently residing in the study area at the time of the baseline data collection were excluded. Ethical approval was provided by both the Waikato and Bay of Plenty Ethics Committees. All participants gave signed informed consent.

\section{Measurements}

Details of the Te Wai o Rona: Diabetes Prevention Strategy have been described previously ${ }^{(17)}$. Briefly, after registration, blood for fasting glucose and lipids (HDL-cholesterol and TAG) was withdrawn and participants invited to undertake a $75 \mathrm{~g} 2 \mathrm{~h}$ oral glucose tolerance test. Glucose was measured by the Roche Hitachi glucose oxidase method (CV $5 \%$ ). Total cholesterol (CV 6\%), HDL-cholesterol (CV 4\%) and TAG (CV 8\%) were determined using a homogeneous enzymic colorimetric system (Roche Modular P800; Roche Diagnostics New Zealand Ltd, Auckland, New Zealand). LDL-cholesterol was then derived using the formula: LDL-cholesterol $=$ (total cholesterol - (TAG/2.2) - HDL-cholesterol). Measurements and questionnaires, including smoking status, were completed after the fasting blood was sampled. Physical activity was kept to a minimum until after the $2 \mathrm{~h}$ blood was sampled for glucose.

Measurements included height without shoes using a stadiometer $(0.5 \mathrm{~cm})$; weight in light clothing and without shoes to the nearest $\pm 0.1 \mathrm{~kg}$ (Wedderburn TI-TH316 Personal scales; Wedderburn TI-BWB800 Personal scales (up to $200 \mathrm{~kg}$ ) for oversize participants); standing waist $\pm 0 \cdot 1 \mathrm{~cm}$ was measured at the lateral mid-point between the lower rib and the iliac crest and the hip circumference $\pm 0.1 \mathrm{~cm}$ at the level of maximum protrusion of the gluteal muscles. WHR and BMI $\left(\mathrm{kg} / \mathrm{m}^{2}\right)$ were derived. Lying hand-to-foot bioimpedance was determined (IMP5, $50 \mathrm{kHz}$; Impedimed, Queensland, Australia) and a Maori-specific validated equation ${ }^{(18)}$ applied. After a minimum rest sitting for $5 \mathrm{~min}$, blood pressure was measured in the supported arm using an Omron T8 electronic sphygmomanometer and a large cuff when necessary for oversize arms $(>32 \mathrm{~cm})$. All measurements were made in duplicate, and repeated if $\pm 10 \mathrm{mmHg}$. Components of the MS were defined using ATPIII criteria ${ }^{(5)}$. Diabetes, impaired glucose tolerance and impaired fasting glucose were defined by WHO criteria ${ }^{(3)}$.

\section{Statistics}

Of the 5240 non-pregnant adults screened for diabetes, 4602 self-identified as Maori (approximately $13 \%$ of the comparably aged Maori population in the recruitment area). Of these, 786 were excluded for missing laboratory data and/or anthropometry and blood pressure measurements. Those without full laboratory data (301 males and 419 females) were on average 5 years younger and $1 \mathrm{BMI}$ unit less than those with such data. Data from the remaining 3816 were used for the present analysis and within these, 204 did not have a technically satisfactory measurement of body fat by bioimpedance. Data were analysed separately by sex. Mean and standard deviations summarised the continuous variables. Subjects were categorised by the presence or absence of risk factors, including smoking and dysglycaemia, impaired fasting glucose, impaired glucose tolerance or diabetes. Impaired fasting glucose was defined as fasting glucose between 6.1 and $6.9 \mathrm{mmol} / \mathrm{l}$; impaired glucose tolerance was defined as $2 \mathrm{~h}$ glucose between 7.9 and $11.0 \mathrm{mmol} / \mathrm{l}$; type 2 diabetes mellitus was defined as fasting glucose $\geq 7.0 \mathrm{mmol} / \mathrm{l}$ or $2 \mathrm{~h}$ glucose $\geq 11.1 \mathrm{mmol} / 1$. If no oral glucose tolerance test was undertaken and the fasting glucose was $\geq 7.0 \mathrm{mmol} / 1$ and/or the random glucose was $\geq 11.1 \mathrm{mmol} / \mathrm{l}$, diabetes was considered to be present. Receiver operating characteristic (ROC) curves, which are plots of the diagnostic sensitivity and specificity of the ability of waist, WHR, BMI or percentage body fat to detect the presence of at least two of the other MS components ( $\geq 2 \mathrm{MS}$ ) or dysglycaemia, were examined. The shortest distance on the ROC curve (optimal sensitivity and specificity) was considered in the determination of cut-offs. Logistic regression analysis was used to determine the OR $(95 \% \mathrm{CI})$ of the presence of $\geq 2 \mathrm{MS}$ or dysglycaemia using the waist cut-off defined by the ROC and adjusted for sex, smoking and age. All statistical analysis was performed using SPSS (version 14; SPSS, Inc., Chicago, IL, USA).

\section{Results}

\section{Descriptive}

Anthropometric measurements besides BMI differed significantly by sex (Table 1) even after adjustment for age. Similarly, metabolic risk factors showed a different profile by sex (adjusted and unadjusted for age) with a higher prevalence of low HDL in women, and higher blood pressure, TAG and fasting glucose in men. Of the population, $42.1 \%$ had $\geq 2 \mathrm{MS}$ besides waist. One in three reported currently smoking and more women than men smoked.

The increasing prevalence of frequency of risk factors within each waist decile is shown in Fig. 1. There is a linear trend $(P<0.0001)$ for an increasing number of risk factors across the range of waist for males and females. It must be noted that in the lowest decile of waist, $53 \%$ of women and $36 \%$ of men are without other MS components and in the highest decile, $6 \%$ of women and $5 \%$ of men have no other MS components.

\section{Sensitivity and specificity analyses}

In males and females, waist was as good a predictor of $\geq 2 \mathrm{MS}$ as BMI or percentage body fat (Table 2). In women, but not men, waist was a better predictor than WHR. Waist circumference of $\geq 2$ MS Maori women and men was 97 and $102 \mathrm{~cm}$ (Table 2). WHR, BMI and percentage body fat were 0.84 $32 \mathrm{~kg} / \mathrm{m}^{2}$ and $42 \%$ for women and $0 \cdot 93,30 \mathrm{~kg} / \mathrm{m}^{2}$ and $30 \%$ for men. The prediction of dysglycaemia using anthropometric 
Table 1. Baseline characteristics of 3816 Maori by sex (Mean values and standard deviations or percentages)

\begin{tabular}{|c|c|c|c|c|c|c|}
\hline & \multicolumn{2}{|c|}{ Women ( $n$ 2472) } & \multicolumn{2}{|c|}{ Men $(n 1344)$} & \multirow[b]{2}{*}{$P^{\star}$} & \multirow[b]{2}{*}{$P$ (age adjusted) $\dagger$} \\
\hline & Mean & SD & Mean & SD & & \\
\hline Age (years) & $47 \cdot 1$ & $12 \cdot 7$ & $48 \cdot 6$ & $13 \cdot 2$ & $<0.0001$ & \\
\hline Weight (kg) & $86 \cdot 2$ & $20 \cdot 7$ & $99 \cdot 6$ & $22 \cdot 0$ & $<0.0001$ & $<0.0001$ \\
\hline Height (cm) & 161.9 & $6 \cdot 0$ & 173.5 & 6.9 & $<0.0001$ & $<0.0001$ \\
\hline BMI $\left(\mathrm{kg} / \mathrm{m}^{2}\right)$ & 32.9 & $7 \cdot 8$ & 33.0 & 6.7 & 0.63 & 0.62 \\
\hline Percentage body fat & $42 \cdot 4$ & $6 \cdot 2$ & 31.4 & $6 \cdot 9$ & $<0.0001$ & $<0.0001$ \\
\hline Waist circumference (cm) & 98.4 & $16 \cdot 4$ & $106 \cdot 6$ & $16 \cdot 9$ & $<0.0001$ & $<0.0001$ \\
\hline Hip circumference $(\mathrm{cm})$ & $114 \cdot 7$ & $15 \cdot 6$ & 111.9 & $13 \cdot 2$ & $<0.0001$ & $<0.0001$ \\
\hline Waist:hip ratio & 0.86 & 0.07 & 0.95 & 0.07 & $<0.0001$ & $<0.0001$ \\
\hline Fasting glucose (mm) & $5 \cdot 2$ & 0.9 & 5.5 & 1.0 & $<0.0001$ & $<0.0001$ \\
\hline TAG $(\mathrm{mm})$ & 1.4 & 0.8 & 1.8 & 1.3 & $<0.0001$ & $<0.0001$ \\
\hline HDL-cholesterol (mm) & 1.4 & 0.4 & $1 \cdot 2$ & 0.4 & $<0.0001$ & $<0.0001$ \\
\hline Systolic blood pressure (mmHg) & 134 & 23 & 140 & 19 & $<0.0001$ & $<0.0001$ \\
\hline Diastolic blood pressure $(\mathrm{mmHg})$ & 89 & 13 & 91 & 13 & $<0.0001$ & 0.001 \\
\hline \multicolumn{7}{|c|}{ Prevalence of metabolic risk factors (\%) } \\
\hline Fasting glucose or diabetes & \multicolumn{2}{|c|}{$21 \cdot 3$} & \multicolumn{2}{|c|}{$34 \cdot 3$} & $<0.0001$ & \\
\hline TAG & \multicolumn{2}{|c|}{23.4} & \multicolumn{2}{|c|}{$35 \cdot 1$} & $<0.0001$ & \\
\hline HDL & \multicolumn{2}{|c|}{$20 \cdot 1$} & \multicolumn{2}{|c|}{$10 \cdot 7$} & $<0.0001$ & \\
\hline Blood pressure & \multicolumn{2}{|c|}{$66 \cdot 9$} & \multicolumn{2}{|c|}{$81 \cdot 3$} & $<0.0001$ & \\
\hline \multicolumn{7}{|c|}{ Prevalence of metabolic risk factors (\%) } \\
\hline No risk factors & \multicolumn{2}{|c|}{$22 \cdot 7$} & \multicolumn{2}{|c|}{$11 \cdot 0$} & $<0.0001$ & \\
\hline One risk factor & \multicolumn{2}{|c|}{$40 \cdot 0$} & \multicolumn{2}{|c|}{$38 \cdot 2$} & & \\
\hline Two risk factors & \multicolumn{2}{|c|}{$23 \cdot 5$} & \multicolumn{2}{|c|}{$32 \cdot 0$} & & \\
\hline Three risk factors & \multicolumn{2}{|c|}{$10 \cdot 8$} & \multicolumn{2}{|c|}{$15 \cdot 8$} & & \\
\hline Four risk factors & \multicolumn{2}{|c|}{3.0} & \multicolumn{2}{|c|}{3.0} & & \\
\hline Smoking now (\%) & \multicolumn{2}{|c|}{$39 \cdot 7$} & \multicolumn{2}{|c|}{31.6} & $<0.0001$ & \\
\hline
\end{tabular}

* Unpaired $t$ test, two-tailed.

$\dagger$ Analysis of covariance: female $v$. male with age as covariate.

variables followed a similar pattern to $\geq 2 \mathrm{MS}$. Optimal thresholds of waist, WHR, BMI and percentage body fat were $98 \mathrm{~cm}, 0.84,33 \mathrm{~kg} / \mathrm{m}^{2}$ and $44 \%$ for women and $103 \mathrm{~cm}, 0.95,33 \mathrm{~kg} / \mathrm{m}^{2}$ and $30 \%$ for men.

\section{Logistic regression}

Using the waist criteria defined by the ROC analysis of $98 \mathrm{~cm}$ for women and $103 \mathrm{~cm}$ for men with adjustment for sex, smoking and age ( 48 years) the adjusted OR for $\geq 2 \mathrm{MS}$ was 3.5 (95\% CI 3.1, 4.0) (Table 3). As OR are multiplicative, a waist greater than 98 or $103 \mathrm{~cm}$ (OR 3.5), being male (OR $1 \cdot 7$ ), smoking (OR 1.3) and aged more than 48 years (OR 1.7) multiplies to the odds of having $\geq 2 \mathrm{MS}$ being 13.1 times higher. If waist were set at 98 or $103 \mathrm{~cm}$ and applying IDF criteria for other risks, then $27.8 \%$ (34.0\% males, $25.5 \%$ females) would be identified with the MS (Table 3). Addition of the Maori BMI cut-off of $32 \mathrm{~kg} / \mathrm{m}^{2}$ to the model

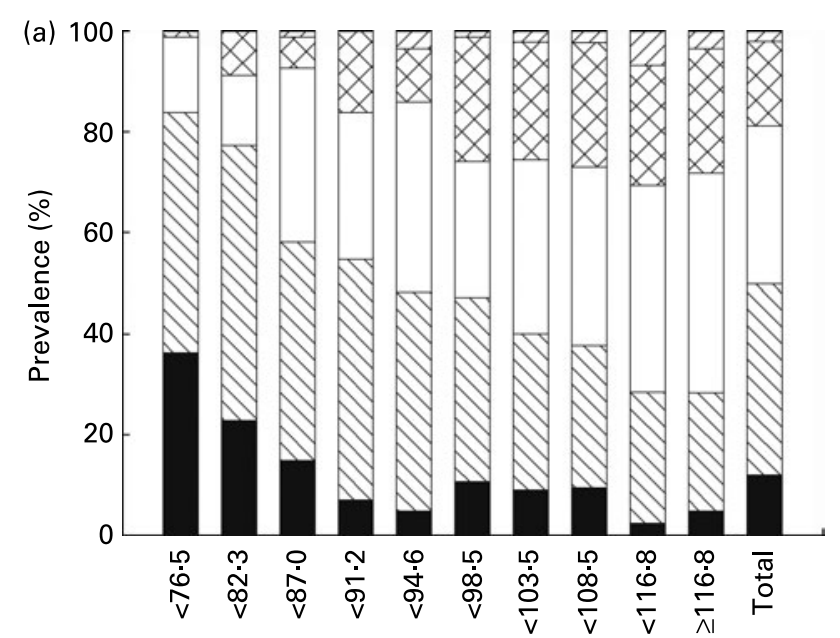

Waist decile $(\mathrm{cm})$

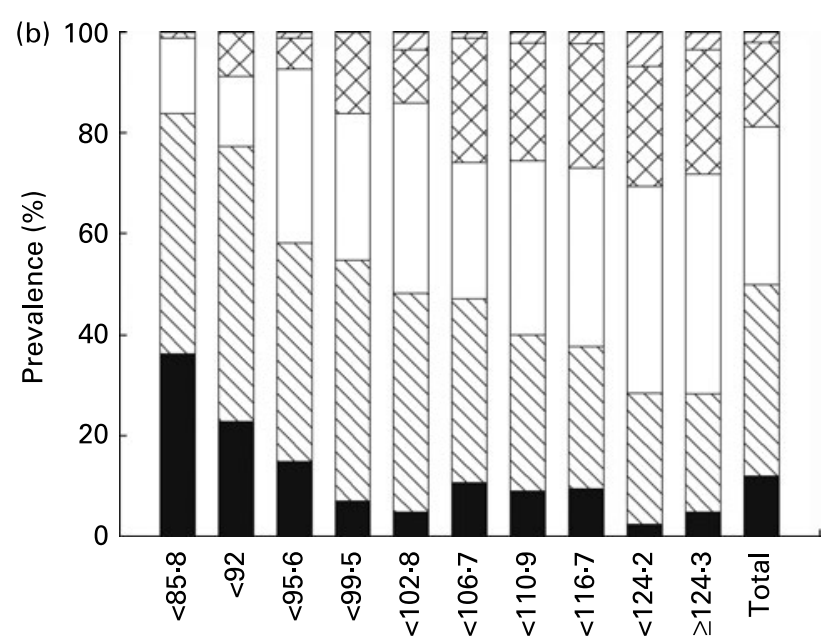

Waist decile $(\mathrm{cm})$

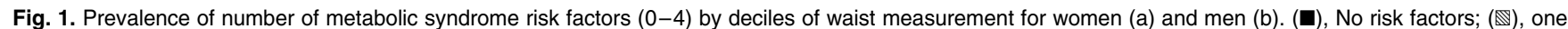

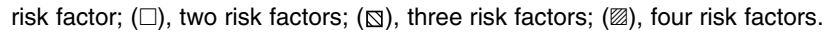


Table 2. Optimal sensitivity and specificity thresholds for the detection of two or more metabolic risk factors and dysglycaemia (diabetes: impaired glucose tolerance or impaired fasting glucose risk) from anthropometric measures

\begin{tabular}{|c|c|c|c|c|c|c|c|}
\hline \multirow[b]{2}{*}{ Sex } & \multirow[b]{2}{*}{ Variable } & \multicolumn{2}{|c|}{ ROC area } & \multirow[b]{2}{*}{$P$} & \multicolumn{2}{|c|}{$\begin{array}{l}\text { Maximum sum of sensitivity } \\
+ \text { specificity }\end{array}$} & \multirow[b]{2}{*}{ Threshold } \\
\hline & & OR & $95 \% \mathrm{Cl}$ & & Sensitivity & Specificity & \\
\hline \multicolumn{8}{|c|}{ Two or more metabolic risk factors } \\
\hline \multirow[t]{4}{*}{ Female } & Waist & 0.73 & $0.71,0.75$ & $<0.0001$ & 0.70 & 0.64 & $97 \mathrm{~cm}$ \\
\hline & Waist:hip ratio & 0.66 & $0.64,0.68$ & $<0.0001$ & 0.72 & 0.53 & 0.84 \\
\hline & BMI & 0.72 & $0.70,0.74$ & $<0.0001$ & 0.69 & 0.64 & $32 \mathrm{~kg} / \mathrm{m}^{2}$ \\
\hline & Percentage body fat & 0.70 & $0.68,0.73$ & $<0.0001$ & 0.76 & 0.56 & $42 \%$ \\
\hline \multirow[t]{4}{*}{ Male } & Waist & 0.68 & $0.65,0.71$ & $<0.0001$ & 0.71 & 0.56 & $102 \mathrm{~cm}$ \\
\hline & Waist:hip ratio & 0.67 & $0.64,0.70$ & $<0.0001$ & 0.78 & 0.47 & 0.93 \\
\hline & BMI & 0.68 & $0.66,0.71$ & $<0.0001$ & 0.79 & 0.49 & $30 \mathrm{~kg} / \mathrm{m}^{2}$ \\
\hline & Percentage body fat & 0.68 & $0.65,0.71$ & $<0.0001$ & 0.74 & 0.53 & $30 \%$ \\
\hline \multicolumn{8}{|c|}{ Dysglycaemia } \\
\hline \multirow[t]{4}{*}{ Female } & Waist & 0.70 & $0.67,0.73$ & $<0.0001$ & 0.73 & 0.58 & $98 \mathrm{~cm}$ \\
\hline & Waist:hip ratio & 0.64 & $0.67,0.75$ & $<0.0001$ & 0.75 & 0.48 & 0.84 \\
\hline & BMI & 0.69 & $0.66,0.72$ & $<0.0001$ & 0.66 & 0.64 & $33 \mathrm{~kg} / \mathrm{m}^{2}$ \\
\hline & Percentage body fat & 0.68 & $0.66,0.71$ & $<0.0001$ & 0.71 & 0.59 & $44 \%$ \\
\hline \multirow[t]{4}{*}{ Male } & Waist & 0.65 & $0.62,0.69$ & $<0.0001$ & 0.74 & 0.50 & $103 \mathrm{~cm}$ \\
\hline & Waist:hip ratio & 0.66 & $0.63,0.70$ & $<0.0001$ & 0.73 & 0.53 & 0.95 \\
\hline & BMI & 0.64 & $0.60,0.68$ & $<0.0001$ & 0.58 & 0.64 & $33 \mathrm{~kg} / \mathrm{m}^{2}$ \\
\hline & Percentage body fat & 0.65 & $0.62,0.69$ & $<0.0001$ & 0.80 & 0.43 & $30 \%$ \\
\hline
\end{tabular}

ROC, receiver operating characteristic.

increased the adjusted multiplicative OR to 18.0 (unadjusted OR for BMI 3.2; $95 \%$ CI 2.9, 3.8).

If any three ATP components are used to define the MS (using the new Maori waist cut-offs) (waist $98 \mathrm{~cm}$ females, $103 \mathrm{~cm}$ males), then $32.4 \%$ (29.0\% females, $38.6 \%$ males) would be identified with the MS. If the original ATPIII waist $_{\text {criteria }}{ }^{(5)}$ are used instead, then $36.6 \%$ (34.6\% females, $40 \%$ males) would be identified with the MS.

\section{Discussion}

The present study is the first in a Maori, or any Polynesian, population showing detailed analysis of waist circumference cut-off points for the detection of dysglycaemia and two or more risk factors for the MS. The waist cut-off for women was $98 \mathrm{~cm}$ and $103 \mathrm{~cm}$ for men. While for men, $102 \mathrm{~cm}$ is the same magnitude as recommended by the ATPIII, for women the waist is larger than the required $88 \mathrm{~cm}$. As more than one-third of the subjects using the criteria of ATPIII are identified as at risk ( $35 \%$ women and $40 \%$ of men), the implications both for healthcare policy and treatment need to be attended to urgently. This prevalence compares well with an earlier study of the prevalence of the MS among Maori aged $>40$ years using ATPIII criteria ${ }^{(19)}$. Two or more risk factors were chosen as the diagnostic criteria to fit the IDF criteria for the MS. From Fig. 1 it can be clearly seen that with increasing waist there is an increase in the prevalence and number of risk factors but there is no clear point where risk increases. Cut-off points are arbitrary and risk exists across the range of waist circumference; further diagnostic tests and treatment depend on resources available. Therefore general public health advice should support maintaining or reducing waist circumference.

Maori compared with Europeans have more central fat and less peripheral fat than Europeans ${ }^{(10,11)}$, have a higher prevalence of obesity ${ }^{(20)}$ and are at more risk for and have a higher

Table 3. Unadjusted and adjusted risk factors for the presence of two or more metabolic risk factors and dysglycaemia

\begin{tabular}{|c|c|c|c|c|c|c|c|c|c|c|}
\hline \multirow[b]{2}{*}{ Risk factor } & \multirow[b]{2}{*}{ Exposed (\%) } & \multirow[b]{2}{*}{ Non-exposed (\%) } & \multicolumn{2}{|c|}{ Unadjusted } & \multicolumn{3}{|c|}{ Adjusted } & \multicolumn{3}{|c|}{ Adjusted* } \\
\hline & & & OR & $95 \% \mathrm{Cl}$ & OR & $95 \% \mathrm{Cl}$ & $\mathrm{P}$ & OR & $95 \% \mathrm{Cl}$ & $P^{\star}$ \\
\hline \multicolumn{11}{|c|}{ Two or more metabolic risk factors (waist $98 \mathrm{~cm}$ female, $103 \mathrm{~cm}$ male and age 48 years) } \\
\hline Waist & $57 \cdot 0$ & $27 \cdot 2$ & $3 \cdot 7$ & $3 \cdot 2,4 \cdot 2$ & 3.5 & $3 \cdot 1,4 \cdot 0$ & $<0.001$ & $2 \cdot 1$ & $1 \cdot 7,2 \cdot 5$ & $<0.001$ \\
\hline Sex (male) & $50 \cdot 7$ & $37 \cdot 4$ & $1 \cdot 7$ & $1 \cdot 5,2 \cdot 0$ & $1 \cdot 7$ & $1.4,1.9$ & $<0.001$ & $1 \cdot 7$ & $1 \cdot 5,2 \cdot 0$ & $<0.001$ \\
\hline Smoking & $42 \cdot 1$ & $42 \cdot 2$ & $1 \cdot 0$ & $0 \cdot 9,1 \cdot 1$ & $1 \cdot 3$ & $1 \cdot 1,1 \cdot 5$ & 0.002 & $1 \cdot 3$ & $1 \cdot 2,1 \cdot 6$ & $<0.001$ \\
\hline Age ( $>48$ years) & 48.5 & $36 \cdot 5$ & 1.6 & $1.4,1.9$ & $1 \cdot 7$ & $1 \cdot 5,2 \cdot 0$ & $<0.001$ & $1 \cdot 8$ & $1 \cdot 6,2 \cdot 1$ & $<0.001$ \\
\hline BMI $\left(\geq 32 \mathrm{~kg} / \mathrm{m}^{2}\right)$ & 56.5 & $28 \cdot 2$ & $3 \cdot 2$ & $2 \cdot 9,3 \cdot 8$ & & & & $2 \cdot 1$ & $1 \cdot 7,2 \cdot 6$ & $<0.001$ \\
\hline \multicolumn{11}{|c|}{ Dysglycaemia (waist $98 \mathrm{~cm}$ female, $103 \mathrm{~cm}$ male and age 48 years) } \\
\hline Waist & $27 \cdot 1$ & $10 \cdot 4$ & $3 \cdot 2$ & $2 \cdot 7,3 \cdot 8$ & $3 \cdot 1$ & $2 \cdot 6,3 \cdot 8$ & $<0.001$ & $2 \cdot 1$ & $1 \cdot 7,2 \cdot 8$ & $<0.001$ \\
\hline Sex (male) & 21.5 & $17 \cdot 2$ & $1 \cdot 3$ & $1 \cdot 0,1 \cdot 5$ & $1 \cdot 2$ & $1 \cdot 0,1 \cdot 4$ & 0.05 & $1 \cdot 2$ & $1 \cdot 0,1 \cdot 5$ & 0.024 \\
\hline Smoking & $15 \cdot 0$ & $21 \cdot 1$ & 0.7 & $0.6,0.8$ & 0.8 & $0.7,1.0$ & 0.05 & 0.9 & $0.7,1.0$ & 0.10 \\
\hline Age ( $\geq 48$ years) & 25.9 & $12 \cdot 5$ & $1 \cdot 3$ & $2 \cdot 1,2 \cdot 9$ & 2.4 & $2 \cdot 0,2 \cdot 9$ & $<0.001$ & 2.5 & $2 \cdot 1,3 \cdot 0$ & $<0.001$ \\
\hline BMI $\left(\geq 32 \mathrm{~kg} / \mathrm{m}^{2}\right)$ & $26 \cdot 4$ & $11 \cdot 4$ & $2 \cdot 8$ & $2 \cdot 3,3 \cdot 3$ & & & & $1 \cdot 7$ & $1 \cdot 3,2 \cdot 2$ & $<0.001$ \\
\hline
\end{tabular}

${ }^{*}$ Model with $\mathrm{BMI} \geq 32 \mathrm{~kg} / \mathrm{m}^{2}$ included. 
prevalence of diabetes $^{(12)}$. In agreement with others ${ }^{(21)}$ we have shown that the utility of the waist measurement is comparable with or better than WHR or BMI to detect the MS and dysglycaemia characteristics. Percentage body fat showed similar utility for the detection of those with metabolic risk or dysglycaemia. However, WHR and BMI have the limitation that two measurements are required and percentage fat is more limiting as the measurement requires both more expensive equipment and skill.

Sexual dimorphism for waist cut-off in Europids has shown a difference of $14 \mathrm{~cm}^{(4,5)}$, while in Japanese ${ }^{(6)}$ there was only a $5 \mathrm{~cm}$ difference (with women having a larger waist) where the cut-off was determined by visceral fat measurements. The waist for Chinese and South Asian men is also larger, $10 \mathrm{~cm}$, than women. We also showed a $5 \mathrm{~cm}$ difference by sex in waist cut-off for Maori, with men having the higher waist.

The debate about the general utility of the diagnosis of the MS includes evidence that for ethnic groups with a small frame size, for example, Asian, the application of the current BMI or ATPIII or IDF waist criteria may underestimate $(22,23)$ the risk and require lower anthropometric cut-points. However, this is the first study to investigate the question of appropriate cut-offs in a population that has a larger frame size and increased muscularity and less fat ${ }^{(10,11)}$ at the same BMI as Europeans. It has been recently shown, using dual X-ray absorptiometry region of interest analysis, that for the same height and weight, total abdominal fat mass of Maori is not different to Europeans ${ }^{(24)}$, which gives rise to further questions about intra-abdominal $v$. subcutaneous fat differences and also differences in skeletal muscle characteristics that we are unable to answer. A further criticism of metabolic risk criteria is that they may not include allowances for the effects of smoking or age ${ }^{(25)}$. While we are able to show increased metabolic risk with smoking, this risk is relatively small compared with the multiplicative risk of waist, age and sex. Prospective studies and robust physical measures such as intimal medial thickening $^{(26)}$ as markers of early disease (before waist may decrease) are required to test the proposed cut-offs. Other Polynesian populations including those in the USA, for example, Hawaiians and Samoans and indigenous populations at high risk also need to test these findings.

There is reassurance that the current BMI cut-off of $32 \mathrm{~kg} /$ $\mathrm{m}^{2}$ used for Maori obesity has some clinical relevance in risk assessment. We are now able to show that waist measurements of $98 \mathrm{~cm}$ for women and $103 \mathrm{~cm}$ for men have similar utility in identifying Maori at risk and in combination with BMI and other risk factors such as smoking and hypertension could be used to justify further evaluation.

There is a range of caveats to the interpretation of these data. The subjects were recruits into a trial of lifestyle change to prevent diabetes which unfortunately did not continue; these data are therefore cross-sectional. Some recruits had missing data (largely fasting blood data) and were not included in this analysis but were to be included within analyses of the impact of the trial on, for example, anthropometry alone. The trial may have attracted those who were symptomatic as it was an opportunity to be screened for diabetes. Conversely, those attending for a lifestyle trial are possibly more likely to lead a healthier life ${ }^{(27)}$ and to have started making healthier food and physical activity choices, which would impact on the risk of dysglycaemia. Notwithstanding this, the vast majority were obese and hence selection bias is unlikely to have had a major impact on the nature of the cohort. The cohort represents approximately $25 \%$ of Maori women and $<15 \%$ of Maori men aged 28 years of more in the area, again suggesting that caution should be used in extrapolating these findings to the wider local or national Maori population.

In conclusion, we have shown that higher waist cut-offs should be used in defining the MS and for clinical studies among Maori. Our data also suggest that BMI might provide additional information regarding CVD risk among Maori.

\section{Acknowledgements}

All authors substantially contributed to the design of the experiment, collection of data, analysis of data, writing of the manuscript, and provision of significant advice and consultation in its preparation. The project was led by D. S. with E. C. R. in the Waikato and N. C. in the Lakes District.

Funding was provided by the Health Research Council (grant number 04/071), Waikato District Health Board, Lakes District Health Board, Ministry of Health, Sport and Recreation New Zealand, Southern Trust, Waikato Local Diabetes Team and Merck Sharp \& Dohme. Support in kind was provided by Roche Diagnostics, Pathlab, Medlab, University of Auckland, Auckland University of Technology, Wintec, Te Hotu Manawa Māori, Eggs Inc., Vodafone, Rivermill Bakers and Sun Fruit. D. S. acknowledges the support of the NIHR Cambridge Biomedical Research Centre.

We thank the investigator group, Kaitiaki, Maori Community Health Workers, Te Wai o Rona: Diabetes Prevention Strategy Project team and local health service staff for their varied contributions to the study.

The authors state that they have no conflicts of interest.

\section{References}

1. Alberti KG \& Zimmet PZ (2008) Should we dump the metabolic syndrome? No. BMJ 336, 641.

2. Gale EA (2008) Should we dump the metabolic syndrome? Yes. BMJ 336, 640.

3. Alberti KG \& Zimmet PZ (1998) Definition, diagnosis and classification of diabetes mellitus and its complications. Part 1: diagnosis and classification of diabetes mellitus provisional report of a WHO consultation. Diabet Med 15, 539-553.

4. International Diabetes Federation (2006) The IDF consensus worldwide definition of the metabolic syndrome. http://www. idf.org/webdata/docs/IDF_Meta_def_final.pdf

5. American Diabetes Association (2001) Executive Summary of the Third Report of the National Cholesterol Education Program (NCEP) Expert Panel on Detection, Evaluation, and Treatment of High Blood Cholesterol in Adults (Adult Treatment Panel III). JAMA 285, 2486-2497.

6. Alberti KG, Zimmet P \& Shaw J (2006) Metabolic syndrome a new world-wide definition. A Consensus Statement from the International Diabetes Federation. Diabet Med 23, 469-480.

7. American Diabetes Association (2004) Standards of medical care in diabetes. Diabetes Care 27, Suppl. 1, S15-S35.

8. James WP (2005) Assessing obesity: are ethnic differences in body mass index and waist classification criteria justified? Obes Rev 6, 179-181. 
9. Hara K, Matsushita Y, Horikoshi M, et al. (2006) A proposal for the cutoff point of waist circumference for the diagnosis of metabolic syndrome in the Japanese population. Diabetes Care 29, 1123-1124.

10. Rush EC, Plank L, Chandu V, et al. (2004) Body size, body composition and fat distribution: comparison of New Zealand European, Pacific Island and Asian Indian young men. $N Z$ Med J 117, http://www.nzma.org.nz/journal/117-1207/1203/

11. Rush EC, Goedecke JH, Jennings C, et al. (2007) BMI, fat and muscle differences in urban women of five ethnicities from two countries. Int J Obes Relat Metab Disord 31, 1232-1239.

12. Joshy G \& Simmons D (2006) Epidemiology of diabetes in New Zealand: revisit to a changing landscape. $N \mathrm{Z} \mathrm{Med} \mathrm{J}$ 119, U1999.

13. Blakely T, Ajwani S, Robson B, et al. (2004) Decades of disparity: widening ethnic mortality gaps from 1980 to 1999 . N $Z$ Med J 117, U995.

14. Pan XR, Li GW, Hu YH, et al. (1997) Effects of diet and exercise in preventing NIDDM in people with impaired glucose tolerance. The Da Qing IGT and Diabetes Study. Diabetes Care 20, 537-544.

15. Tuomilehto J, Lindstrom J, Eriksson JG, et al. (2001) Prevention of type 2 diabetes mellitus by changes in lifestyle among subjects with impaired glucose tolerance. $N$ Engl J Med 344, $1343-1350$.

16. Knowler WC, Barrett-Connor E, Fowler SE, et al. (2002) Reduction in the incidence of type 2 diabetes with lifestyle intervention or metformin. $N$ Engl J Med 346, 393-403.

17. Lim S, Chellumuthi C, Crook N, et al. (2008) Low prevalence of retinopathy, but high prevalence of nephropathy among Maori with newly diagnosed diabetes - Te Wai o Rona: Diabetes Prevention Strategy. Diabetes Res Clin Pract 80, 271-274.

18. Swinburn BA, Ley SJ, Carmichael HE, et al. (1999) Body size and composition in Polynesians. Int J Obes Relat Metab Disord 23, $1178-1183$.
19. Simmons D \& Thompson CF (2004) Prevalence of the metabolic syndrome among adult New Zealanders of Polynesian and European descent. Diabetes Care 27, 3002-3004.

20. Ministry of Health (2003) A Portrait of Health: Key Results of the 2002/2003 New Zealand Health Survey. Wellington: Ministry of Health.

21. Klein S, Allison DB, Heymsfield SB, et al. (2007) Waist circumference and cardiometabolic risk: a consensus statement from shaping America's health: Association for Weight Management and Obesity Prevention; NAASO, the Obesity Society; the American Society for Nutrition; and the American Diabetes Association. Diabetes Care 30, $1647-1652$.

22. Lear SA, Humphries KH, Kohli S, et al. (2007) The use of BMI and waist circumference as surrogates of body fat differs by ethnicity. Obesity 15, 2817-2824.

23. Huxley R, James WP, Barzi F, et al. (2008) Ethnic comparisons of the cross-sectional relationships between measures of body size with diabetes and hypertension. Obes Rev 9, Suppl. 1, $53-61$.

24. Rush E, Freitas I \& Plank L (2009) Body size, body composition and fat distribution: comparative analysis of European, Maori, Pacific Island and Asian Indian adults. $\mathrm{Br} J \mathrm{Nutr}$ (epublication ahead of print version 10 February 2009).

25. Calle EE, Thun MJ, Petrelli JM, et al. (1999) Body-mass index and mortality in a prospective cohort of U.S. adults. $N$ Engl $J$ Med 341, 1097-1105.

26. Matoba Y, Inoguchi T, Nasu S, et al. (2008) Optimal cut points of waist circumference for the clinical diagnosis of metabolic syndrome in the Japanese population. Diabetes Care 31, 590-592.

27. Buckley B, Murphy AW, Byrne M, et al. (2007) Selection bias resulting from the requirement for prior consent in observational research: a community cohort of people with ischaemic heart disease. Heart 93, 1116-1120. 